\title{
Tropical cyclone-related socio-economic losses in the western North Pacific region
}

\author{
C. Welker ${ }^{1,2, *}$ and E. Faust ${ }^{2}$ \\ ${ }^{1}$ Deutsches Zentrum für Luft- und Raumfahrt (DLR), Institut für Physik der Atmosphäre, Münchner Straße 20, \\ 82234 Oberpfaffenhofen, Germany \\ ${ }^{2}$ Munich RE, Geo Risks Research/Corporate Climate Centre, Königinstraße 107, 80802 Munich, Germany \\ *now at: University of Bern, Oeschger Centre for Climate Change Research and Institute of Geography, \\ Hallerstraße 12, 3012 Bern, Switzerland
}

Correspondence to: C. Welker (christoph.welker@giub.unibe.ch)

Received: 30 April 2012 - Revised: 16 November 2012 - Accepted: 27 November 2012 - Published: 24 January 2013

\begin{abstract}
The western North Pacific (WNP) is the area of the world most frequently affected by tropical cyclones (TCs). However, little is known about the socio-economic impacts of TCs in this region, probably because of the limited relevant loss data. Here, loss data from Munich RE's NatCatSERVICE database is used, a high-quality and widely consulted database of natural disasters. In the country-level loss normalisation technique we apply, the original loss data are normalised to present-day exposure levels by using the respective country's nominal gross domestic product at purchasing power parity as a proxy for wealth. The main focus of our study is on the question of whether the decadal-scale TC variability observed in the Northwest Pacific region in recent decades can be shown to manifest itself economically in an associated variability in losses. It is shown that since 1980 the frequency of TC-related loss events in the WNP exhibited, apart from seasonal and interannual variations, interdecadal variability with a period of about $22 \mathrm{yr}-$ driven primarily by corresponding variations of Northwest Pacific TCs. Compared to the long-term mean, the number of loss events was found to be higher (lower) by $14 \%$ (9\%) in the positive (negative) phase of the decadal-scale WNP TC frequency variability. This was identified for the period 19802008 by applying a wavelet analysis technique. It was also possible to demonstrate the same low-frequency variability in normalised direct economic losses from TCs in the WNP region. The identification of possible physical mechanisms responsible for the observed decadal-scale Northwest Pacific TC variability will be the subject of future research, even if suggestions have already been made in earlier studies.
\end{abstract}

\section{Introduction}

Tropical cyclones (TCs) are among the most destructive natural disasters in East and Southeast Asia. Variations in disaster severity resulting from TCs are attributable, on the one hand, to the variability in hazardous weather conditions such as extreme wind speeds, storm surge, and rainfall; and on the other hand to socio-economic developments such as changes in population, exposure, and damage susceptibility.

The frequency of TCs over the western North Pacific (WNP) is higher than in any other ocean basin, with about one-third of the globally recorded TCs occurring there (Ritchie and Holland, 1999). China is the nation most frequently affected by TCs. On average, about seven TCs make landfall in China each year (Zhang et al., 2009). In the WNP, TCs occur all year round, but most occur in the period from July to November (Neumann, 1993).

Apart from this seasonal variability, previous studies showed that TCs in the Northwest Pacific vary on both interannual and interdecadal time scales. Interannual variations in WNP TCs were associated with modes of internal climate variability. The El Niño-Southern Oscillation (ENSO) has been considered to be one of the dominant factors affecting the interannual variability of TC frequency (e.g. Chan, 2000; Wang and Chan, 2002; Elsner and Liu, 2003) and intensity (e.g. Camargo and Sobel, 2005) over the Northwest Pacific, having an influence on the frequency of TCs landfalling along the east and southeast Asian coast (e.g. Saunders et al., 2000; Liu and Chan, 2003; Wu et al., 2004; Yin et al., 2010). ENSO's extreme phases, El Niño and La Niña, 
are marked by changes in the atmospheric and oceanic conditions that influence the formation, intensification, and movement of WNP TCs (Welker, 2010). In the El Niño phase, the region in which Northwest Pacific TCs typically develop is further east and south, towards the equator. This can be attributed to corresponding displacements of atmospheric and oceanic conditions favourable to TC genesis. Consequently, in the El Niño phase, WNP TCs form at a greater distance from the Asian continent and have more time to intensify before they make landfall and weaken. Moreover, due to El Niño-related changes in the large-scale atmospheric circulation, TCs which form in tropical areas east of the Philippines tend to be steered poleward, rather than westward into the South China Sea. In the La Niña phase, the situation is almost reversed.

In the last few decades, TC frequency decreased considerably over the South China Sea but increased over subtropical East Asia (e.g. Wu et al., 2005; Wang et al., 2011). These changes seem to be linked with long-term shifts in the prevailing TC tracks in the WNP, which in turn are attributed to the observed westward extension of the North Pacific subtropical high (Zhou et al., 2009).

Interdecadal TC variations in the WNP appear to be related to low-frequency changes in atmospheric and oceanic conditions influencing the genesis, intensification, and track of TCs (e.g. Yumoto and Matsuura, 2001; Matsuura et al., 2003; Ho et al., 2004; Chan, 2005, 2008; Liu and Chan, 2008; Chan and Xu, 2009; Kubota and Chan, 2009; Goh and Chan, 2010; Wang et al., 2010; Yeh et al., 2010), while the tracks of WNP TCs seem to be modulated largely by the location, strength, and extent of the North Pacific subtropical high pressure area. Some studies attribute these variations to alterations in coupled atmosphere-ocean phenomena on similar time scales such as ENSO or Pacific Decadal Oscillation (PDO). For instance, examining the period from 1965 to 2008, Wang et al. (2010) demonstrated that TC activity in the WNP basin, as measured by the number of storm days, exhibited decadalscale variability, with high TC activity in the 1990s. Their data indicated that this period with high TC activity in the Northwest Pacific basin coincided with the prolonged El Niño episode from 1990 to 1994 and the anomalously strong El Niño event of 1997. Investigating a longer sample period from 1945 to 2004, Chan and Xu (2009) found similar interdecadal variability in the frequency of TCs throughout the WNP and in the landfall frequency of TCs along the East Asian coast. Furthermore, they showed that the TC landfall frequency along the East Asian coast is well correlated with the basin-wide number of TCs in the WNP for periods between 16 and $32 \mathrm{yr}$ in length. This indicates that in periods of above-average TC frequency in the WNP, enhanced activity of TCs landfalling in East Asia is also likely. At shorter time scales, this is not necessarily the case.

Obviously, many previous studies have dealt with variations in Northwest Pacific TCs on different time scales. Even recent papers on TC losses in China (Zhang et al., 2009;
Gemmer et al., 2011) indicate that still relatively little is known about the direct economic and social impacts of TCs in East and Southeast Asia. Hence, the main objectives of this study are, on the one hand, to determine the dominant modes of variability in TC-related losses in the Northwest Pacific region and, on the other, to answer the question of whether a dominant mode of climate and TC variability in the WNP can be shown to "break through" in economic terms and manifest itself in an associated variability in losses. Identifying possible physical mechanisms responsible for the observed variability of WNP TCs (and related losses) will be the subject of future analyses, even though suggestions have already been made in previous studies.

\section{Data and methods}

\subsection{Loss event frequency}

We used data from NatCatSERVICE (data retrieved in December 2010; see Kron et al., 2012), Munich RE's global loss database, to quantify the socio-economic impacts of TCs in the WNP. In this study, WNP is defined as the region extending from $0^{\circ}$ to $50^{\circ} \mathrm{N}$ and from $100^{\circ} \mathrm{E}$ to $160^{\circ} \mathrm{E}$, and thus comprising large parts of East and Southeast Asia as well as groups of islands in the Pacific. Current records document more than 28000 loss events involving natural hazards. The database contains both geophysical and meteorological loss events. The data set is considered to document most of the loss events that occurred from 1980 up to the present (Neumayer and Barthel, 2011; Kron et al., 2012).

Time series of the monthly numbers of TC-related loss events in the WNP were computed for the period from 1980 to 2008. At the same time, this period served as the base period for identifying monthly frequency anomalies. We calculate monthly anomalies in the usual way by subtracting the climatological mean for the reference period, computed for each month of the year, from the respective monthly value. In this way, the seasonal variability is eliminated in the monthly data we analyse. For time series analysis, the loss frequency time series was standardised. Hence, the diagrams are scaled in units of standard deviation with zero mean. Moreover, we analysed the spatial distribution of loss events caused by TCs in the WNP. For this purpose, the WNP was divided into grid boxes measuring $1^{\circ}$ latitude $\times 1^{\circ}$ longitude. The monthly number of TC-related loss events was determined for each grid box during the period from 1980 to 2008. As the number of grid boxes per unit area increases with increasing latitude, the loss event frequency calculated for each grid box was normalised using an area reduction factor.

\subsection{Normalisation of economic loss}

Trends in reported natural disaster losses are influenced by many factors. Besides changes in the actual hazards, these trends are affected by processes such as rising population, 
migration to and settlement in particularly exposed regions such as coasts, improving standards of living, and/or reporting bias. At present, normalising losses to the current level of exposed wealth for the Northwest Pacific region is difficult, i.e. scaling up past losses as if they had occurred under current economic and social conditions, as has been done, e.g. for TC damage in the USA (e.g. Pielke Jr. and Landsea, 1998; Pielke Jr. et al., 2008; Schmidt et al., 2010) or for windstorm losses in Europe (Barredo, 2010). The reason is that, for a large number of countries in East and Southeast Asia, there are hardly any suitable proxies for representing the destroyable wealth of both earlier years and the present. Additionally, due to data limitations we had to spatially resolve at country level.

Hence, we applied a country-level method of normalising economic losses (originally given in US dollars of the event year) resulting from WNP TCs which were obtained from the NatCatSERVICE database for the period from 1980 to 2008. With this approach, the original loss data were normalised to year-of-2008 levels of exposure by using the nominal gross domestic product at purchasing power parity (denoted as GDPPPP in the following) as a proxy for wealth, i.e. accounting for temporal changes in destructible wealth at the country level. GDPPPP is provided in international dollars, whereby an international dollar has the same purchasing power over GDP as a US dollar has in the United States (World Bank, 2012). Hence, inter-country purchasing power differences were taken into account by adjusting losses for purchasing power parities. Each TC loss in the WNP since 1980 was first multiplied by the GDPPPP of the relevant country and reference year (here, 2008) and then divided by that country's GDPPPP in the year of the event (the loss data we use is available on a country basis). This loss normalisation technique was recently also applied by, for example, Pielke Jr. et al. (2003) and Neumayer and Barthel (2011) to data on economic losses resulting from natural disasters in other regions of the world. We obtained GDPPPP data from the World Bank (World Bank, 2011). The data are collected for most of the countries in the Northwest Pacific region on a yearly basis and in most cases are available for the entire period under consideration. The World Bank GDPPPP data was supplemented with GDPPPP data from the IHS Global Insight data set (last access in February 2011) in case the World Bank data set contained no GDPPPP data for the relevant country in the year of the event. This measure was justified by the finding that the difference between the two data sets' GDPPPP figures is negligible for most of the countries in the WNP. Only in very few cases was a loss event recorded in Munich RE's NatCatSERVICE database without there being corresponding GDPPPP data for the relevant country and event year in either the World Bank or the IHS Global Insight database, with the result that it was not possible to normalise the losses in these cases.

In this way, we computed time series of monthly normalised TC damage in the Northwest Pacific region from
1980 to 2008 . We used this period as the base period to calculate monthly loss anomalies and standardised the series for time series analysis. We also examined the spatial distribution of normalised TC losses in the WNP analogous to Sect. 2.1.

\subsection{TC frequency}

The frequency of TCs in the WNP was computed based on the International Best Track Archive for Climate Stewardship (IBTrACS) data set (Knapp et al., 2010), which combines estimates of storm position and intensity from many agencies. As data from the pre-satellite era, before about 1970, are considered less reliable, our calculations have been done using data from 1970 to 2008 . The monthly number of WNP TCs of at least tropical storm intensity (referred to simply as the number of TCs, unless otherwise indicated) according to the Saffir-Simpson Hurricane Scale (SSHS; Simpson, 1974) was computed for this period, representing at the same time the reference period used to calculate monthly frequency anomalies. In this study, we also differentiated between minor to moderate TCs (i.e. of at least tropical storm intensity, but of no more than Category-2 intensity according to the SSHS) and major TCs (i.e. of at least SSHS Category-3 intensity). For time series analysis, the WNP TC frequency time series were standardised.

\subsection{Wavelet analysis}

A powerful way of analysing time series containing nonstationary power at different frequencies is through the method of wavelet analysis. Torrence and Compo (1998) and Grinsted et al. (2004) give a very helpful treatise of the wavelet analysis technique. We used the wavelet software by Torrence and Compo (2012) and Grinsted et al. (2012).

In general, the wavelet analysis technique is used to decompose a time series into time and frequency space simultaneously so that both the dominant modes of variability and the temporal variation of these modes can be determined (Torrence and Compo, 1998). The continuous wavelet transform (CWT) is suited for identifying localised periodic oscillations in time series (Grinsted et al., 2004). For its calculation, we used the Morlet wavelet function, which is basically a sine wave multiplied by a Gaussian envelope. As the wavelet is not completely localised in time, the CWT reveals artefacts at the edges (Grinsted et al., 2004). The cone of influence (COI) denotes the region of the wavelet spectrum in which edge effects cannot be neglected. Caution is therefore advisable in interpreting findings from inside the COI.

According to Grinsted et al. (2004), the statistical significance of wavelet power is assessed relative to the null hypothesis that the signal is generated by a stationary process with a given mean or background power spectrum. To determine the significance level of wavelet power, it is assumed that the sample analysed is nearly normally distributed and 
Table 1. Average frequency of TC-related loss events per year, mean number of fatalities per event, and average original and normalised overall economic losses per event (in US \$ m) for a selection of countries in the WNP in the period from 1980 to 2008.

\begin{tabular}{|c|c|c|c|c|c|}
\hline & Japan & South Korea & China & Taiwan & Philippines \\
\hline $\begin{array}{l}\text { Number of loss } \\
\text { events per year }\end{array}$ & 4.2 & 1.5 & 5.6 & 3.1 & 5.7 \\
\hline $\begin{array}{l}\text { Fatalities per } \\
\text { event }\end{array}$ & 9 & 29 & 51 & 11 & 115 \\
\hline $\begin{array}{l}\text { Economic losses } \\
\text { per event (US \$ m) }\end{array}$ & 458 & 304 & 237 & 56 & 33 \\
\hline $\begin{array}{l}\text { Normalised losses } \\
\text { per event (US \$ m) }\end{array}$ & 694 & 547 & 924 & 116 & 79 \\
\hline
\end{tabular}

has red noise characteristics which can be modelled with a first-order autoregressive (AR1) process. In this study, a peak of wavelet power is considered to be statistically significant if it exceeds the $5 \%$ significance level against red noise.

In addition, we used the wavelet transform as a bandpass filter to isolate individual frequency ranges in a time series and to analyse the temporal variability in these bands independently of one another (referred to as wavelet-filtered time series), as proposed by Torrence and Compo (1998).

The cross wavelet transform (XWT) is a common tool for determining whether two time series are linked (Grinsted et al., 2004), which in the light of a plausible physical mechanism may be deemed a causal link. The XWT, which is calculated from the CWTs of the two time series, shows the common power of the two CWTs and their phase relationship. Wavelet coherence (WTC) can be looked upon as the local correlation between two CWTs, from which it is calculated (Grinsted et al., 2004). The WTC can identify local coherence between two CWTs even if the common power in the XWT is low. The significance level of the WTC is computed using Monte Carlo methods.

\subsection{Statistical tests}

We used the non-parametric Wilcoxon rank-sum test (Wilks, 2006) to test the hypothesis that two samples have the same mean of distribution against the hypothesis that they differ. In this study, two samples are regarded as having significantly different means of distribution if they differ at the $5 \%$ significance level.

The statistical significance of the Pearson correlation coefficient between two time series was derived on the basis of a bootstrap technique (the number of surrogates equalled $100000)$. Here, we consider a correlation to be statistically significant if it is different from zero at the $5 \%$ significance level.
Table 2. Linear correlation coefficients for various combinations of the time series of yearly TC-related losses in the Northwest Pacific region and of the annual WNP TC frequency time series, respectively, from 1980 to 2008 . Correlations statistically significant at the $5 \%$ significance level are plotted in bold.

\begin{tabular}{lrrrr}
\hline & $\begin{array}{r}\text { Number of } \\
\text { loss events }\end{array}$ & $\begin{array}{r}\text { Original } \\
\text { losses }\end{array}$ & $\begin{array}{r}\text { Normalised } \\
\text { losses }\end{array}$ & $\begin{array}{r}\text { Number } \\
\text { of TCs }\end{array}$ \\
\hline Number of loss events & - & $\mathbf{0 . 5 0}$ & $\mathbf{0 . 6 8}$ & 0.35 \\
Original losses & & - & $\mathbf{0 . 6 9}$ & 0.06 \\
Normalised losses & & & - & $\mathbf{0 . 5 0}$ \\
Number of TCs & & & & - \\
\hline
\end{tabular}

\section{Results}

\subsection{Climatology and interannual variability}

In total, about 750 TC-related loss events have been recorded in the NatCatSERVICE database for the WNP in the period from 1980 to 2008. Large parts of the WNP region were affected by TCs (Fig. 1). From 1980 to 2008, most loss events caused by TCs occurred in the Philippines and China, each of which suffered on average six events per year, followed by Japan with approximately four events per year (Table 1). While TCs caused a large number of fatalities in the Philippines (involving an average of approximately 115 fatalities per event), mean normalised overall economic losses were highest in China (about US \$ 0.9 bn per event) and Japan (approximately US $\$ 0.7$ bn per event).

Both the frequency of loss events caused by TCs in the WNP and their associated (original) economic losses were as a rule at high levels from July to November. The correlation between the annual number of TC-related loss events and the yearly frequency of WNP TCs was relatively weak ( $r=0.35$ ) in the period from 1980 to 2008 and statistically significant only at the $10 \%$ significance level (see Table 2). While the correlation for the latter period between the annual number of Northwest Pacific TCs and the yearly aggregated non-normalised overall economic damage caused by WNP TCs is nearly zero $(r=0.06)$ and statistically insignificant, the two time series have a statistically significant correlation $(r=0.50)$ after loss normalisation. In other words, after accounting for changes in socio-economic conditions, we obtain a much better and statistically significant correlation between the hazard and the actual monetary loss. This indicates that the loss normalisation method we applied is reasonable. The correlation between the time series of the yearly number of TC loss events in the WNP and the time series of the yearly TC-related economic losses in the Northwest Pacific region from 1980 to 2008 is 0.50 before and 0.68 after loss normalisation, and in both cases statistically significant. Figure 2 shows that from 1980 to 2008, both TC-related losses in the WNP and WNP TC frequency exhibited a strong interannual variability, superimposed on a low-frequency variability of decadal time scale. 


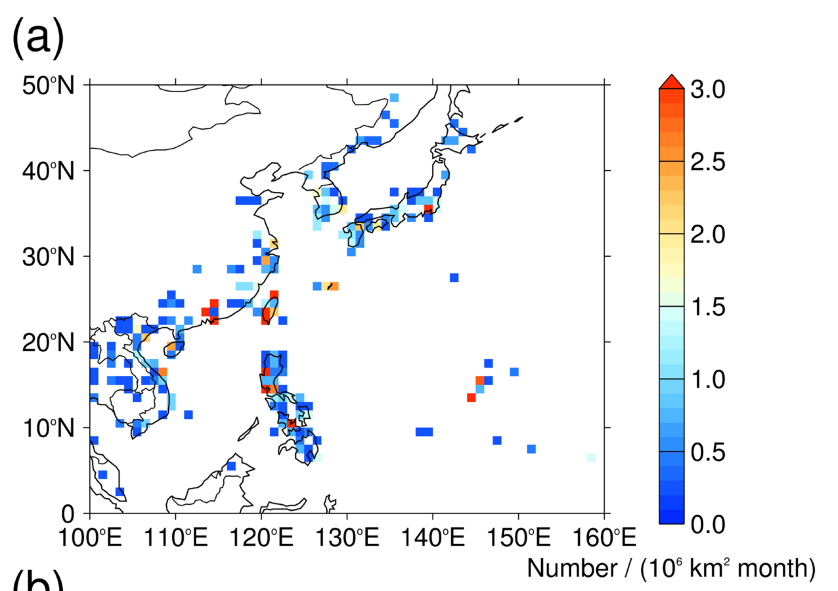

(b)

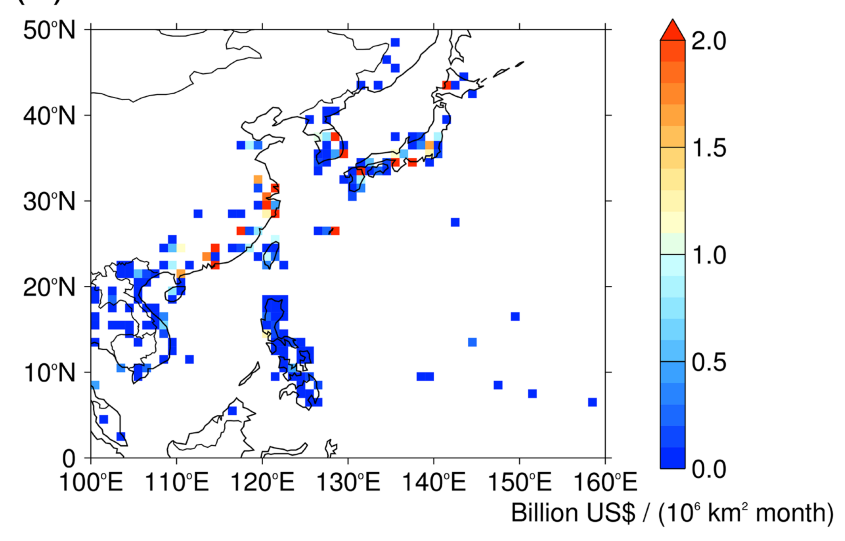

Fig. 1. (a) Average number of TC-related loss events in the WNP per $10^{6} \mathrm{~km}^{2}$ and month in the period from 1980 to 2008 . Grid boxes with frequencies equal to zero are plotted in white. (b) Same as (a) but for mean normalised overall economic losses (the reference year for the normalisation is 2008) resulting from Northwest Pacific TCs in US $\$$ bn per $10^{6} \mathrm{~km}^{2}$ and month. Besides coastal regions of East and Southeast Asia, Northwest Pacific groups of islands were also affected by TCs (coloured grid boxes over ocean areas).

Apparently, both TC activity and related losses in the WNP were comparatively high in the 1990s. Wang et al. (2010) showed, as was already hinted at, the same result for the total number of storm days in the Northwest Pacific (Fig. 4 in their paper), using best-track data provided by the Joint Typhoon Warning Center (JTWC). The WNP TC figure time series in our Fig. 2 is also very similar to the corresponding time series of Northwest Pacific TC frequency shown in Fig. 6a in Chan and Xu (2009). They used TC data obtained from the JTWC and analysed longer TC frequency time series that started in the 1940s. From their analyses, one can infer that the decadal-scale variability in WNP TC frequency shown in our Fig. 2 is obviously part of a temporally stable oscillation. This will be discussed in more detail in the following section.

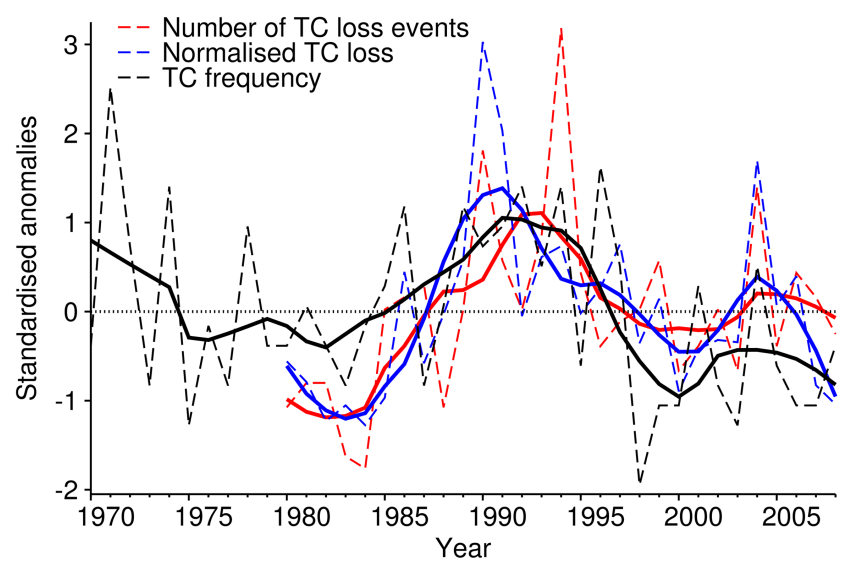

Fig. 2. Standardised time series for the WNP in the period from 1970 (or 1980, respectively) to 2008 of the annual number of TCrelated loss events (red dashed line), of the yearly aggregated normalised overall economic losses caused by TCs (blue dashed line), and of the annual number of TCs (black dashed line). The corresponding smoothed time series are shown as thick solid lines.

\subsection{Interdecadal variability}

In Fig. 2, we smoothed interannual variability by applying a local weighted polynomial regression smoother to the original time series of TC losses and number of TCs, which uses a least-squares fit within a moving window (method according to Cleveland, 1979). We chose a window width of $10 \mathrm{yr}$ and a degree of polynomial within the window of 2 . The aforementioned low-frequency variability can now be identified easily, and we detect what seem to be relatively coordinated swings of roughly decadal time scale. To analyse this variability in a more thorough statistical manner, we applied wavelet analysis first to the time series of the standardised anomalous monthly number of loss events caused by TCs in the WNP from 1980 to 2008, and then to the corresponding time series of normalised overall economic losses. The CWT power spectra of the two time series are shown in Fig. 3a and b, respectively. Figure $3 \mathrm{c}$ shows the CWT of the standardised anomalous monthly frequency of WNP TCs from 1970 to 2008. There are evidently common features in the wavelet power of the analysed time series, such as the regions of statistically significant wavelet power at lower frequencies. This indicates that TCs and associated losses in the WNP have varied on interdecadal time scales over the past 30 or $40 \mathrm{yr}$, respectively. Although these results are from within the COI due to the limited length of the time series, we consider them reliable not only because we found immediate evidence of decadal-scale variability in the time-series-filtering approach shown in Fig. 2, but also because there is evidence of this low-frequency variability in TCs in other studies analysing longer TC time series from other sources and using different statistical methodology. 


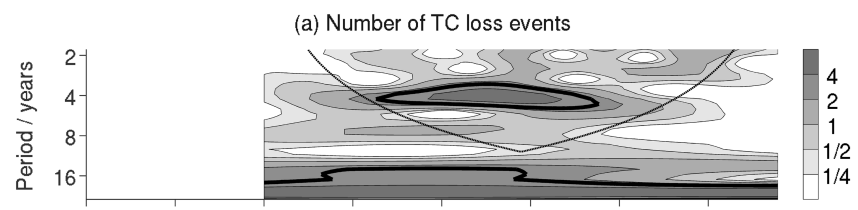

(b) Normalised TC loss

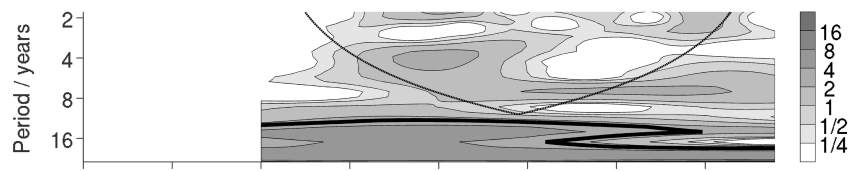

(c) TC frequency

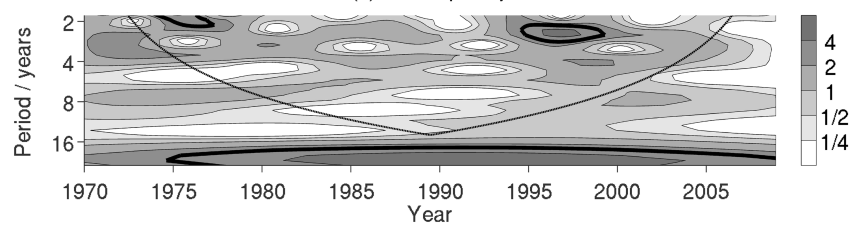

Fig. 3. CWT power spectra of the standardised anomalous monthly (a) frequency of TC-related loss events, (b) normalised overall economic losses caused by TCs in the WNP (note the different grey scale), and (c) number of WNP TCs from 1970 (or 1980, respectively) to 2008. The abscissa indicates the time (year) and the ordinate is the Fourier period (in years). The black enclosing contour lines show the $5 \%$ significance level. The thin black line indicates the COI, where edge effects become important. The number of TCs time series (and TC-related loss event frequency and normalised economic loss time series, respectively) is nearly perfectly (close to) normally distributed and has an AR1 coefficient of $0.13(-0.04$ and -0.03).

Most of the statistically significant wavelet power in the global wavelet spectrum, i.e. in the time-averaged CWT spectrum, of the standardised anomalous monthly number of TC loss events in the Northwest Pacific region from 1980 to 2008 is concentrated at longer periods (Fig. 4). The absolute maximum is observable at a period of $22 \mathrm{yr}$. By contrast, comparatively little wavelet power is concentrated within the characteristic ENSO band, i.e. at periods between two and seven years (El Niño and La Niña events typically recur every two to seven years). Normalised overall economic losses caused by WNP TCs seem to have varied on similar time scales in the period from 1980 to 2008 . In the corresponding global wavelet spectrum, little statistically significant wavelet power is concentrated within the ENSO band, while most of the power is observable at longer periods. The absolute maximum of wavelet power, which is furthermore statistically significant, is again at a period of $22 \mathrm{yr}$. The global wavelet spectrum of the standardised anomalous monthly frequency of TCs over the WNP from 1970 to 2008 is similar to the spectra of TC losses in the WNP, with an absolute maximum of wavelet power at a period of $22 \mathrm{yr}$.

Comparison of the wavelet spectra in Figs. 3 and 4, also considering the different lengths of the time series analysed, indicates that both TC-related losses and the number of TCs in the WNP have their maximum statistically significant

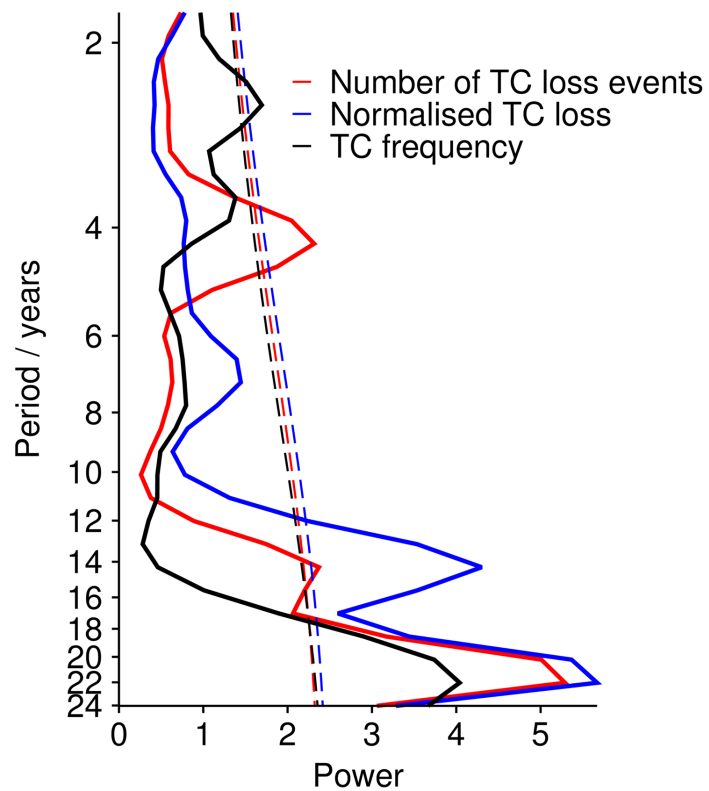

Fig. 4. Global wavelet power spectra of the standardised anomalous monthly number of TC-related loss events (solid red curve) and normalised overall economic losses caused by TCs (solid blue curve) in the WNP from 1980 to 2008 and of the standardised anomalous monthly frequency of WNP TCs from 1970 to 2008 (solid black curve). The abscissa is the wavelet power and the ordinate is the Fourier period in years. The dashed lines denote the $5 \%$ significance level.

wavelet power at a period of $22 \mathrm{yr}$. Given this periodicity supported by wavelet analysis results, the indication of Fig. 2, and the physically causative chain of tropical cyclones that produce losses at landfall, it seems clear that (climate-driven) variation in TCs in the Northwest Pacific region manifests itself in the interdecadal oscillation of the number of TCrelated loss events in this region. Can we now demonstrate this correlation in a statistically convincing way?

To answer this question, we calculated the XWT from the CWTs of the time series of WNP TC figures and TC-related loss event frequency from 1980 to 2008 (Fig. 5a). In the sectors with statistically significant, high common power at periods of about twenty years, the phase relationship between the number of TCs and the TC-related loss event frequency in the WNP is mostly in-phase. Again, even though these results are from within the COI, they are deemed reliable for the reasons stated previously. Figure $5 \mathrm{~b}$ shows the squared WTC of the WNP TC frequency and the TC-related loss event frequency. The squared WTC is quite high (approximately 0.8 ) at periods of about twenty years, even though it is only partially statistically significant and again inside the COI. From 1980 to 2008, the WNP TC-related loss event frequency time series and the time series of normalised overall economic losses caused by Northwest Pacific TCs also reveal statistically significant, high common power at periods of about twenty years, are mostly in-phase in this range, and 


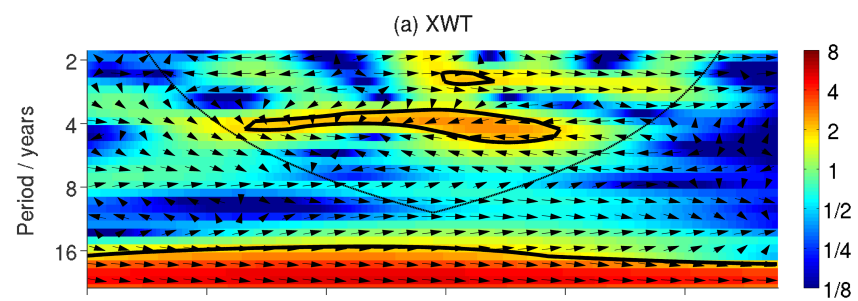

(b) WTC

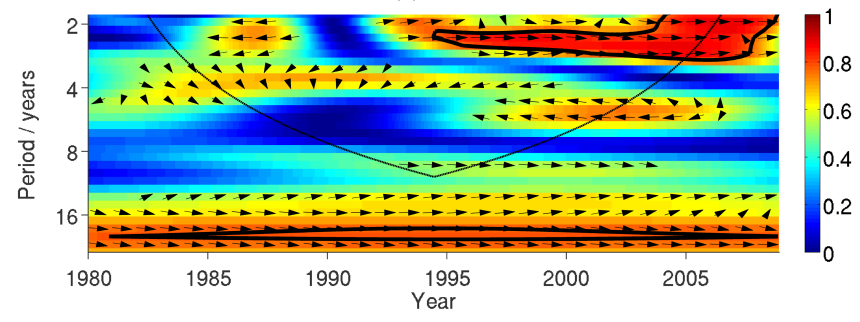

Fig. 5. (a) XWT and (b) squared WTC of the standardised anomalous monthly number of TCs and TC-related loss event frequency time series for the WNP region in the "overlapping" period from 1980 to 2008. Arrows indicate the relative phase relationship (inphase pointing right, anti-phase pointing left). Black contour lines designate the $5 \%$ significance level and the COI is indicated by a thin black line.

have very high, statistically significant squared WTC values (no figure).

In spite of the relatively short length of the time series analysed, we see evidence that at interdecadal time scales (i.e. at periods of about $22 \mathrm{yr}$ ) variations in the frequency of TC-related loss events in the WNP were linked with corresponding variations in Northwest Pacific TCs. To support this assertion, we constructed a 22-yr, wavelet-filtered time series of both the standardised anomalous monthly number of loss events caused by TCs in the WNP from 1980 to 2008, and the standardised anomalous monthly WNP TC frequency from 1970 to 2008 (Fig. 6). For the overlapping period from 1980 to 2008 , the correlation between the two filtered time series is good. This (together with the previous results) suggests that on interdecadal time scales, or rather at periods of $22 \mathrm{yr}$, the variability in the frequency of losses caused by TCs in the WNP was largely governed by corresponding TC variations. Furthermore, Fig. 6 reveals that the derived interdecadal variability in the frequency of WNP TCs can be understood particularly as a variability in minor to moderate TCs (and to a lesser extent in major TCs).

The size of the TC and loss data sample we analysed is, as was already mentioned, small for a full determination of interdecadal variations. However, interdecadal changes in Northwest Pacific TCs derived in previous studies (e.g. Fig. 1 in Yumoto and Matsuura, 2001; Fig. 6b in Chan and $\mathrm{Xu}, 2009$ ), which used other TC best-track data, are comparable to ours. The authors of these studies deduced similar periods of variability and showed the temporal stability of

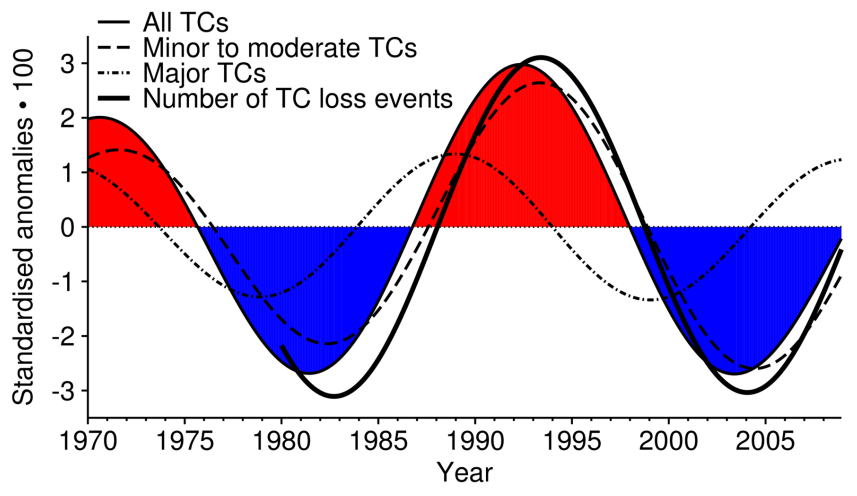

Fig. 6. 22-yr, wavelet-filtered time series of the standardised anomalous monthly frequency of TCs that reached tropical storm intensity (thin solid line), of minor to moderate TCs (dashed line; see text for TC intensity definitions), of major TCs (dot-dashed line), and of TC-related loss events (thick solid line) in the WNP from 1970 (or 1980 , respectively) to 2008. Red (blue) areas indicate plus (minus) phases in interdecadal Northwest Pacific TC variability.

these variations by analysing longer TC frequency time series that started back in the 1940s and 1950s, respectively. The interdecadal WNP TC variations found in this work for a relatively short sample period of about four decades can therefore be seen as part of a temporally stable oscillation.

On the basis of the 22-yr, wavelet-filtered time series of the standardised anomalous monthly Northwest Pacific TC frequency from 1970 to 2008, we identified phases of high and low WNP TC activity. Months with positive (negative) values for this filtered TC frequency were classified as phase plus (minus). The sample of the anomalous monthly number of Northwest Pacific TC-related loss events for a plus phase and the corresponding sample for a minus phase have mean distributions that differ statistically significantly. On average, the number of TC-related loss events in the WNP was anomalously high in plus phases (+3.5 loss events per 12 months) and anomalously low in minus phases $(-2.2$ loss events per 12 months). Compared to the long-term mean number of loss events caused by TCs in the Northwest Pacific region (25.8 loss events per 12 months), the number of loss events increased by approximately $14 \%$ in plus phases and decreased by $9 \%$ in minus phases. Accordingly, the mean distributions of the anomalous monthly TC frequency over the WNP for plus phases and of the corresponding sample for minus phases differ statistically significantly. In plus phases, the anomalous number of TCs in the Northwest Pacific was, on average, positive ( +2.6 TCs per 12 months), but was negative in minus phases ( -2.0 TCs per 12 months). In plus (minus) phases, the TC frequency in the WNP was about $10 \%$ higher (or $7 \%$ lower, respectively) than the climatological average (26.7 TCs per 12 months).

Figure 7 shows that at a period of $22 \mathrm{yr}$, the variability in the number of TC-related loss events in the WNP and the variability in normalised overall economic losses caused 


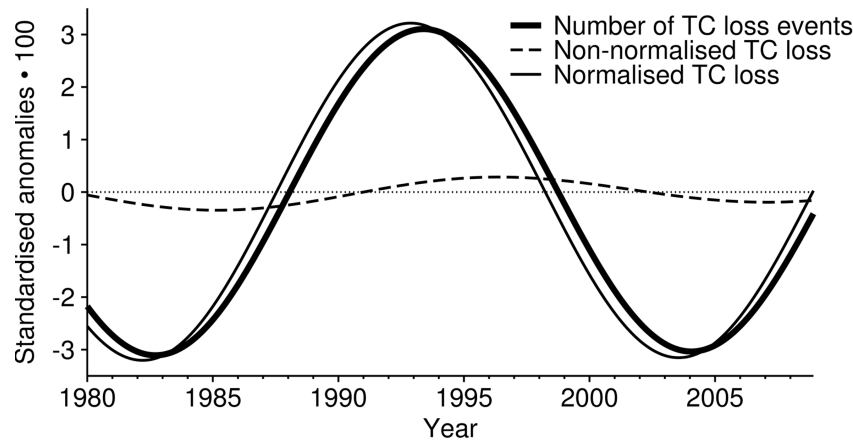

Fig. 7. 22-yr, wavelet-filtered time series of the standardised anomalous monthly frequency of TC-related loss events (thick solid line) and of the standardised anomalous monthly non-normalised and normalised overall economic TC losses (dashed and thin solid line) in the WNP from 1980 to 2008.

by Northwest Pacific TCs were mostly in-phase from 1980 to 2008. It is also evident that this finding applies only to normalised, not to original TC losses. In plus phases - as covered by our sample - we find an increase in the mean normalised economic losses of $46 \%$ vis-a-vis the long-term mean (US $\$ 10.4$ bn per 12 months). In minus phases, the average normalised economic loss was found to be $29 \%$ lower than the base state. Certainly, this can be seen only as a rough indication of the amplitude, given that we have only slightly more than one complete period covered by data.

\section{Conclusions and outlook}

We analysed TC-related socio-economic losses in the Northwest Pacific region. A complete normalisation of economic losses in this region is not possible at the present time due to the lack of relevant and complete data on socio-economic developments. In the first step, we applied a country-level loss normalisation approach based on the relevant country's nominal gross domestic product (at purchasing power parity) at the year of the event. As was shown by Barredo et al. (2012) for the case of Spain, there might be an underestimation of the change in exposed wealth over time by using GDP as a proxy, in particular as we cover fast-growing economies. As a consequence of this limitation of the method applied in this study, spurious trends of normalised losses might be involved due to the underestimation.

Although, strictly speaking, the available sample of TC loss data for the WNP is too small for a full determination of interdecadal variations, our analyses indicate that in recent decades the number of loss events caused by TCs in the WNP varied on interdecadal time scales, at periods of about $22 \mathrm{yr}$. On these time scales, changes in the frequency of TCrelated loss events in the Northwest Pacific region seemed to be linked with variations in WNP TC activity. The latter TC variations are very similar to those found in earlier studies (e.g. Yumoto and Matsuura, 2001; Chan and Xu, 2009; Wang et al., 2010). The responsible physical mechanisms need to be identified better in future research, although some suggestions have already been made in former studies. As has been pointed out in this paper, there is evidence to suggest that not only the frequency of loss events caused by TCs in the WNP but also the (normalised) property losses resulting from landfalling TCs are modulated by low-frequency climate variations in the Northwest Pacific region.

Zheng et al. (2000) present an interesting approach to reducing edge effects in the wavelet time-frequency spectrum by using a numerical method prior to the wavelet transform to extend the time series on both ends (see their paper for details). This could enhance their ability to reveal lowfrequency signals in the time series. We aim to apply this method to the number of TCs and losses time series we analysed in this paper.

In addition to TC frequency, we plan to link socioeconomic TC losses in the WNP with alternative measures of TC activity or intensity such as the Power Dissipation Index (PDI) introduced by Emanuel (2005). The PDI is an index of a TC's destructive potential. We think that such an index would probably be a better proxy for the potential destructiveness of TCs in the WNP region than the basin-wide TC frequency we applied. The annual number of tropical storm days in the WNP, as described by Wang et al. (2010), might be another suitable metric. It combines information about the frequency and lifespan of TCs.

In a further step, we aim to divide the WNP into subregions, for instance into a southern (i.e. coastal regions of southern China, Vietnam, and the Philippines), middle (i.e. Taiwan and coastal regions of northern China), and northern region (i.e. Korean Peninsula and Japan) as proposed by Chan and $\mathrm{Xu}$ (2009) and to analyse the temporal variability in TCs and particularly in associated losses in these regions independently of each other. These analyses appear to hold promise, as not only the TC climatology but also the population density and the concentration of wealth at risk is geographically variable in the WNP.

Acknowledgements. This research was funded by Munich RE. It was carried out at Munich RE's Geo Risks Research/Corporate Climate Centre, at DLR's Institute of Atmospheric Physics, and at the Oeschger Centre for Climate Change Research and Institute of Geography of the University of Bern. We are very grateful to Robert Sausen from the DLR and Nikolai Dotzek, who died unexpectedly on 29 May 2010, for their support in this research. Wavelet software was provided by C. Torrence and G. Compo, and is available at http://atoc.colorado.edu/research/wavelets/. Additionally, A. Grinsted, J. C. Moore, and S. Jevrejeva made cross wavelet and wavelet coherence software available (http://www.pol.ac.uk/home/research/waveletcoherence/).

Edited by: M.-C. Llasat

Reviewed by: two anonymous referees 


\section{References}

Barredo, J. I.: No upward trend in normalised windstorm losses in Europe: 1970-2008, Nat. Hazards Earth Syst. Sci., 10, 97-104, doi:10.5194/nhess-10-97-2010, 2010.

Barredo, J. I., Saurí, D., and Llasat, M. C.: Assessing trends in insured losses from floods in Spain 1971-2008, Nat. Hazards Earth Syst. Sci., 12, 1723-1729, doi:10.5194/nhess-12-17232012, 2012.

Camargo, S. J. and Sobel, A. H.: Western North Pacific tropical cyclone intensity and ENSO, J. Climate, 18, 2996-3006, 2005.

Chan, J. C. L.: Tropical cyclone activity over the western North Pacific associated with El Niño and La Niña events, J. Climate, 13, 2960-2972, 2000.

Chan, J. C. L.: Interannual and interdecadal variations of tropical cyclone activity over the western North Pacific, Meteorol. Atmos. Phys., 89, 143-152, 2005.

Chan, J. C. L.: Decadal variations of intense typhoon occurrence in the western North Pacific, Proc. R. Soc. A, 464, 249-272, 2008.

Chan, J. C. L. and Xu, M.: Inter-annual and inter-decadal variations of landfalling tropical cyclones in East Asia. Part 1: Time series analysis, Int. J. Climatol., 29, 1285-1293, 2009.

Cleveland, W. S.: Robust locally weighted regression and smoothing scatterplots, J. Am. Stat. Assoc., 74, 829-836, 1979.

Elsner, J. B. and Liu, K. B.: Examining the ENSO-typhoon hypothesis, Climate Res., 25, 43-54, 2003.

Emanuel, K.: Increasing destructiveness of tropical cyclones over the past 30 years, Nature, 436, 686-688, 2005.

Gemmer, M., Yin, Y., Luo, Y., and Fischer, T.: Tropical cyclones in China: County-based analysis of landfalls and economic losses in Fujian Province, Quatern. Int., 244, 169-177, 2011.

Goh, A. Z.-C. and Chan, J. C. L.: Interannual and interdecadal variations of tropical cyclone activity in the South China Sea, Int. J. Climatol., 30, 827-843, 2010.

Grinsted, A., Moore, J. C., and Jevrejeva, S.: Application of the cross wavelet transform and wavelet coherence to geophysical time series, Nonlinear Proc. Geoph., 11, 561-566, 2004.

Grinsted, A., Moore, J. C., and Jevrejeva, S.: Cross wavelet and wavelet coherence, http://www.pol.ac.uk/home/research/ waveletcoherence/ (last access: March 2012), 2012.

Ho, C.-H., Baik, J.-J., Kim, J.-H., Gong, D.-Y., and Sui, C.-H.: Interdecadal changes in summertime typhoon tracks, J. Climate, 17, 1767-1776, 2004.

Knapp, K. R., Kruk, M. C., Levinson, D. H., Diamond, H. J., and Neumann, C. J.: The International Best Track Archive for Climate Stewardship (IBTrACS), B. Am. Meteorol. Soc., 91, 363376, 2010.

Kron, W., Steuer, M., Löw, P., and Wirtz, A.: How to deal properly with a natural catastrophe database - analysis of flood losses, Nat. Hazards Earth Syst. Sci., 12, 535-550, doi:10.5194/nhess12-535-2012, 2012.

Kubota, H. and Chan, J. C. L.: Interdecadal variability of tropical cyclone landfall in the Philippines from 1902 to 2005, Geophys. Res. Lett., 36, L12802, doi:10.1029/2009GL038108, 2009.

Liu, K. S. and Chan, J. C. L.: Climatological characteristics and seasonal forecasting of tropical cyclones making landfall along the South China coast, Mon. Weather Rev., 131, 1650-1662, 2003.

Liu, K. S. and Chan, J. C. L.: Interdecadal variability of western North Pacific tropical cyclone tracks, J. Climate, 21, 4464-4476, 2008.
Matsuura, T., Yumoto, M., and Iizuka, S.: A mechanism of interdecadal variability of tropical cyclone activity over the western North Pacific, Clim. Dynam., 21, 105-117, 2003.

Neumann, C. J.: Global overview, in: Global Guide to Tropical Cyclone Forecasting, edited by: Holland, G. J., World Meteorological Organization, Geneva, Switzerland, 1.1-1.56, 1993.

Neumayer, E. and Barthel, F.: Normalizing economic loss from natural disasters: A global analysis, Global Environ. Chang., 21, 1324, 2011.

Pielke Jr., R. A. and Landsea, C. W.: Normalized hurricane damages in the United States: 1925-1995, Weather Forecast., 13, 621631, 1998.

Pielke Jr., R. A., Rubiera, J., Landsea, C., Fernández, M. L., and Klein, R.: Hurricane vulnerability in Latin America and the Caribbean: normalized damage and loss potentials, Nat. Hazards Rev., 4, 101-114, 2003.

Pielke Jr., R. A., Gratz, J., Landsea, C. W., Collins, D., Saunders, M. A., and Musulin, R.: Normalized hurricane damage in the United States: 1900-2005, Nat. Hazards Rev., 9, 29-42, 2008.

Ritchie, E. A. and Holland, G. J.: Large-scale patterns associated with tropical cyclogenesis in the western Pacific, Mon. Weather Rev., 127, 2027-2043, 1999.

Saunders, M. A., Chandler, R. E., Merchant, C. J., and Roberts, F. P.: Atlantic hurricanes and NW Pacific typhoons: ENSO spatial impacts on occurrence and landfall, Geophys. Res. Lett., 27, 1147-1150, 2000.

Schmidt, S., Kemfert, C., and Höppe, P.: The impact of socioeconomics and climate change on tropical cyclone losses in the USA, Reg. Environ. Change, 10, 13-26, 2010.

Simpson, R. H.: The hurricane disaster potential scale, Weatherwise, 27, p. 169 and p. 186, 1974.

Torrence, C. and Compo, G. P.: A practical guide to wavelet analysis, B. Am. Meteorol. Soc., 79, 61-78, 1998.

Torrence, C. and Compo, G. P.: Wavelet software, http://atoc. colorado.edu/research/wavelets/ (last access: March 2012), 2012.

Wang, B. and Chan, J. C. L.: How strong ENSO events affect tropical storm activity over the western North Pacific, J. Climate, 15, 1643-1658, 2002.

Wang, B., Yang, Y., Ding, Q.-H., Murakami, H., and Huang, F.: Climate control of the global tropical storm days (1965-2008), Geophys. Res. Lett., 37, L07704, doi:10.1029/2010GL042487, 2010.

Wang, R., Wu, L., and Wang, C.: Typhoon track changes associated with global warming, J. Climate, 24, 3748-3752, 2011.

Welker, C.: Vorhersagbarkeit tropischer Zyklone und ihrer versicherungsrelevanten Schäden im indopazifischen Raum, Ph.D thesis (published in German), Ludwig-Maximilians-Universität München, DLR-Forschungsbericht 2010-27, 148 pp., 2010.

Wilks, D. S.: Statistical Methods in the Atmospheric Sciences, 2nd Edn., International Geophysics Series, Academic Press, 627 pp., 2006.

World Bank: The World Bank databank, http://databank.worldbank. org/ddp/home.do?Step=1\&id=4/ (last access: February 2011), 2011.

World Bank: World Development Indicators database, http://data. worldbank.org/data-catalog/GDP_PPP_based_table, (last access: November 2012), 2012.

Wu, M. C., Chang, W. L., and Leung, W. M.: Impacts of El Niño/Southern Oscillation events on tropical cyclone landfalling 
activity in the western North Pacific, J. Climate, 17, 1419-1428, 2004.

Wu, L., Wang, B., and Geng, S.: Growing typhoon influence on East Asia, Geophys. Res. Lett., 32, L18703, doi:10.1029/2005GL022937, 2005.

Yeh, S.-W., Kang, S.-K., Kirtman, B. P., Kim, J.-H., Kwon, M.-H., and Kim, C.-H.: Decadal change in relationship between western North Pacific tropical cyclone frequency and the tropical Pacific SST, Meteorol. Atmos. Phys., 106, 179-189, 2010.

Yin, Y., Gemmer, M., Luo, Y., and Wang, Y.: Tropical cyclones and heavy rainfall in Fujian Province, China, Quatern. Int., 226, 122$128,2010$.
Yumoto, M. and Matsuura, T.: Interdecadal variability of tropical cyclone activity in the western North Pacific, J. Meteorol. Soc. Jpn., 79, 23-35, 2001.

Zhang, Q., Wu, L., and Liu, Q.: Tropical cyclone damages in China 1983-2006, B. Am. Meteorol. Soc., 90, 489-495, 2009.

Zheng, D., Chao, B. F., Zhou, Y., and Yu, N.: Improvement of edge effect of the wavelet time-frequency spectrum: application to the length-of-day series, J. Geodesy, 74, 249-254, 2000.

Zhou, T., Yu, R., Zhang, J., Drange, H., Cassou, C., Deser, C., Hodson, D. L. R., Sanchez-Gomez, E., Li, J., Keenlyside, N., Xin, X., and Okumura, Y.: Why the western Pacific subtropical high has extended westward since the late 1970's, J. Climate, 22, 21992215, 2009. 